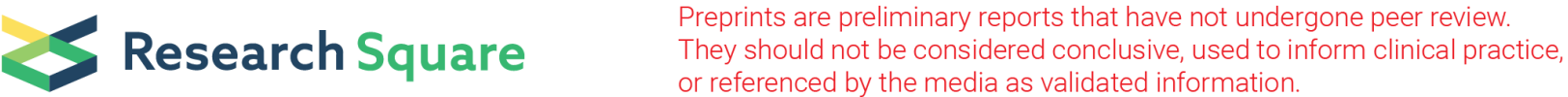

\section{Changes in children with cerebral palsy after six months of hippotherapy: A clinical trial applying rehabilitation treatment taxonomy}

Juliana MP Starling

FHEMIG/Cersat

Ana Paula B Gontijo

Universidade Federal de Minas Gerais

Rosana F Sampaio

Universidade Federal de Minas Gerais

Juliana V Mambrini

Fundacao Oswaldo Cruz Instituto Rene Rachou

Sergio T Fonseca

Universidade Federal de Minas Gerais

Marisa Cotta Mancini ( $\nabla$ marisacmancini@gmail.com )

Universidade Federal de Minas Gerais https://orcid.org/0000-0002-7415-5043

Research article

Keywords: Rehabilitation; Treatment classification; Equine-assisted therapy; Children with disabilities

Posted Date: April 12th, 2019

DOl: https://doi.org/10.21203/rs.2.9143/v1

License: (9) (i) This work is licensed under a Creative Commons Attribution 4.0 International License. Read Full License 


\section{Abstract}

Background Hippotherapy is a complementary therapeutic modality that seeks to promote functional changes in children with cerebral palsy (CP). Knowledge of the direct and indirect changes resulting from this therapy will help identify which groups of children with cerebral palsy can benefit from this type of therapy. The present study aimed to analyze the effects of hippotherapy for children with cerebral palsy with regard to age, topography, and severity using the rehabilitation treatment taxonomy. Methods We conducted a before-after clinical trial. Thirty-one children with $\mathrm{CP}$, stratified by age (4-7 years; 8-12 years), severity (mild, moderate, severe), topography (hemiplegia, diplegia, quadriplegia) and previous time in hippotherapy (3-6 months, over 6 months) underwent individual weekly 30-minute hippotherapy sessions for 6 months in addition to regular rehabilitation. Postural control and balance were evaluated by the Early Clinical Assessment of Balance (ECAB). Secondary outcome measures included the Gross Motor Function Measure (GMFM) and the Cerebral Palsy Quality of Life for Children self-report of the primary caregiver questionnaire. Blinding was used for scoring the outcome measures. Results Postural control and balance and gross motor function showed small improvements after 6 months of intervention, with larger effects in dimensions $D$ and $E$ of the children's gross motor function. These changes were influenced by the severity and topography of the CP. The taxonomy of rehabilitation treatments structured the interpretation of the hippotherapy effects, identifying the possible mechanism of action (horse's step and movement demands), active ingredients (activation of muscles involved in postural correction, vestibular and visual stimuli), target outcomes (postural control and balance) and indirect outcomes (gross motor function and quality of life). Conclusion Hippotherapy sessions, in addition to rehabilitation, produced small, but positive changes in motor and psychosocial outcomes in children with CP. The benefits varied from 3 to 7 points in postural control and balance (ECAB) and in all dimensions of the GMFM. The changes in gross motor function were influenced by the type and severity of CP.

\section{Background}

Recent proposals of the taxonomy of treatments in rehabilitation have offered two approaches for analyzing rehabilitation interventions: treatment theory (TT) and enablement theory (ET) $[1,2,3,4]$. TT specifies the mechanisms by which the active ingredients of a treatment cause changes in the target outcome, that is, the functioning variable that is directly affected by the intervention $[3,4]$. ET expands the analysis of the intervention impact to include functioning, allowing the listing of other benefits that may indirectly emerge from the intervention $[3,4]$. The effects of an intervention should be investigated in relation to the characteristics of the individuals. As such, the treatment can be customized to the specifics of the client [4]. To our knowledge, hippotherapy has not been analyzed from these perspectives. Currently available evidence hinders an adequate measure of the effects of hippotherapy based on the different characteristics of the participants.

Hippotherapy is a complementary therapy in which perturbations and stimuli are generated by the gait of a horse as a therapeutic element to improve posture, balance and gross movement of the individual $[5,6]$. The mechanical, vestibular and visual stimuli resulting from the horse's movement is thought to stimulate 
the postural control of children with cerebral palsy (CP). As hippotherapy sessions are conducted in an outdoor environment, this intervention provides the client with close contact with nature and with the animal, which may positively impact psychosocial domain outcomes $[7,8]$. From the perspective of rehabilitation treatment taxonomy (RTT), hippotherapy may bring clinically important motor and psychosocial benefits to children with $\mathrm{CP}[7,8,9,10]$.

Identifying direct and indirect changes resulting from hippotherapy, outlining the mechanisms that produce such effects, and identifying groups of children with cerebral palsy who will benefit most from this intervention will help to structure and advance current knowledge. This study used RTT to evaluate changes in postural control and balance, gross motor function and quality of life (QOL) of children with $\mathrm{CP}$ after six months of hippotherapy. It also sought to determine whether the observed changes were influenced by individual factors, such as the child's age or CP severity and topography, and/or the amount of time that the child attended hippotherapy.

\section{Methods}

\section{Study Design}

This study was a pre-post clinical trial with a 6-month intervention period. Measurements were taken at the beginning of the study $\left(T_{1}\right)$ and 6 months $\left(T_{2}\right)$ after the initial evaluation. The trial was retrospectively registered on June 07, 2018 (number: NCT03548376).

\section{Participants}

Thirty-one children with medical diagnoses of $\mathrm{CP}$ who attended the Equestrian Center of the Alferes Tiradentes Cavalry Regiment (CERCAT) hippotherapy program for at least 3 months participated in the study. Only children aged 4 to 12 years who had no other CP-associated diagnoses (e.g., autism) were included. Participants were stratified by CP severity (mild, moderate or severe), age (4-7 years, 8-12 years), the topography of the involved limbs (hemiplegia, diplegia or quadriplegia) and previous time of hippotherapy (3-6 months, more than 6 months).

The severity of CP was classified by the Gross Motor Function Classification System (GMFCS) [11], which consists of five ordinal categories based on the mobility and use of support devices by children with CP. Participants at GMFCS levels I and II were classified as having mild severity, participants at level III were classified as having moderate severity, and participants at levels IV and V were classified as having severe impairment. We used the translated and adapted GMFCS version [12]. 
The study's procedures were explained to all children who attended the hippotherapy service and met the inclusion criteria and to their legal guardians. Written informed consent was obtained from the participants prior to data collection. Guardians provided written consent for their children and assent was secured from adolescents. This study's protocol was approved by the Research Ethics Committee of the Universidade Federal de Minas Gerais (Certificate of Presentation for Ethical Consideration, CAAE: 42678815.3.0000.5149).

\section{Instrumentation}

\section{Descriptive Variables}

The children's caregivers were interviewed and provided information on the therapies performed by the child, the age and educational level of the caregiver, the caregiver's relationship with the child and the family's socioeconomic status (SES) [13]. Other information about the child, including the topography of the affected limbs, GMFCS level, age, sex and previous time of hippotherapy, were collected from the service's medical records.

\section{Postural Control and Balance}

The Early Clinical Assessment of Balance (ECAB) $[14,15]$ estimates the postural stability of the child according to head and trunk controls in static activities (i.e., prone, sitting and standing) and postural control in dynamic activities (i.e., sitting to standing and standing activities). Scores assigned to the 13 ECAB items were summed, resulting in a total score of 100 . The higher the score, the better the child's postural control.

\section{Gross Motor Function}

The Gross Motor Function Measure (GMFM)-88 includes five dimensions: (A) lying and rolling, (B) sitting, (C) crawling and kneeling, (D) standing and (E) walking, running and jumping. The GMFM-88 generates a score for each dimension and a total score. Higher scores represent a greater repertoire of a child's gross motor function $[16,17,18]$.

\section{Quality of Life}

The Quality of Life Questionnaire for Children with Cerebral Palsy: questionnaire for primary caregivers (CPQOL-Child) $[19,20]$ provides information regarding the wellbeing of children with CP between 4 and 12 
years of age and was administered in an interview with key caregivers. This version has 66 questions organized in seven QOL domains: social wellbeing and acceptance, functioning, participation and physical health, emotional wellbeing and self-esteem, access to services, pain and disability impact and family health [19]. Scores were transformed into domain-specific percentages [19].

\section{Intervention: Hippotherapy}

The intervention was administered for 30 minutes weekly at the CERCAT and was conducted by equestrian therapists (physiotherapists or occupational therapists) qualified by the Brazilian Association of Hippotherapy.

The horses were trained for hippotherapy practice, and each patient used the same animal in all sessions. The specific hippotherapy gear included safety straps, riding blankets, stirrups and saddles with and without support straps. Use of protective helmets was mandatory in all sessions. Playful and educational toys were also used. The participants included the patient, the equestrian therapist, the horse handler (the professional who drives the horse) and, when necessary, an auxiliary helper to ensure the safety of the child.

The hippotherapy sessions were individualized. The goals set by the therapist were based on the individual demands and the motor ability level of each client. The therapeutic plans were grounded on previously published hippotherapy protocols $[6,10,21,22,23,24]$. The activities proposed during each session sought to stimulate the postural control of the child. Such activities could be performed in various postures (i.e., classic, inverted, lateral, dorsal decubitus, ventral decubitus and standing on the stirrups). They included demands for stability and balance (i.e., trunk rotation activities, movements in various directions and bimanual tasks), active stretches and antigravitational exercises during riding, integrated with ludic-cognitive resources (i.e., memory games and identification of colors, numbers, and letters).

For the most part, children with mild and moderate impairments rode individually and were encouraged to maintain an upright posture throughout the session. Those with more severe impairment were encouraged to maintain control and postural alignment, with the minimum of support being provided. In some cases, it was necessary to use a double riding strategy in which the therapist rode the horse along with the patient to help and stimulate the child's postural control on the animal. Throughout the session, the horse varied its speed, cadence and direction according to the therapist's command, using different paths (i.e., circles, zigzags, and straight lines) and crossed different types of terrain (i.e., uphill, downhill, 
dirt, asphalt and grass). All participants were instructed to continue with their rehabilitation routines (i.e., physical therapy, occupational therapy and others).

\section{Procedures}

All instruments were administered by a trained examiner, and the sessions were recorded with a Sony DCR-SX $21^{\circledR}$ digital camcorder.

In this longitudinal study, an examiner who was not involved in the data collection (evaluations and intervention) scored the GMFM-88. This examiner watched the videos and was blinded to the child's descriptive information and the order of the evaluation ( $T_{1}$ or $\left.T_{2}\right)$. The ECAB test score was calculated by two other external examiners who watched the videos and were also blinded regarding the same information. The CPQOL-Child administration was performed by the same examiner, with no access to the child's previous $T_{2}$ score.

The examiners who performed the data collection were previously trained in the administration procedures of each outcome measure, and their consistency was assessed in relation to another experienced examiner. The consistency of the independent examiners who scored the CPQOL-Child, GMFM-88, and ECAB was assessed in evaluations of eight children with CP who were not in the sample group. The indices obtained in the test-retest and interexaminer reliabilities (intraclass correlation coefficient -ICC) ranged from 0.99 to 1.00 .

Participants were recruited in September and October 2016. The trial started in November 2016 and ended in August 2017. The trial ended after the 6-month intervention period.

\section{Data Analysis}

Paired t-tests analyzed changes on postural control and balance, gross motor function and the domains of CPQOL-Child between $T_{1}$ and $T_{2}$. The interaction between the independent factors with three levels (severity and topography) and time $\left(T_{1}, T_{2}\right)$ on each outcome was preceded by the test of equality of variances across groups. When this assumption was held, ANOVA was used to test whether the difference between times varied across groups. When the normality assumption was violated, the Kruskal-Wallis test was used to evaluate time $\mathrm{x}$ group interactions. A post hoc test identified effects on 
bivariate comparisons. The interaction between the independent factors with two levels (age and previous time of hippotherapy) and time $\left(T_{1}, T_{2}\right)$ on the outcomes was also preceded by normal distribution checks in each group (Shapiro-Wilk). When normality of distributions was identified, t-tests were employed to verify whether the difference between the time points varied in the two groups. When the assumption was violated, a nonparametric alternative (Wilcoxon's test) was used. The data analysis was conducted using information from all recruited participants $(n=31)$.

\section{Results}

Descriptive information of the children and their caregivers is shown in Table 1.

Results from inferential analyses conducted with parametric tests are reported as mean difference between $T_{1}$ and $T_{2}$ and $95 \%$ confidence interval. For the variables in which the differences between times did not follow normal distribution, median of group difference and the interval of variation of the differences (interquartile range P25, P75), are presented.

\section{Postural Control and Balance}

Significant improvements in the postural control and balance of children with CP were found. ECAB scores increased by 6 points ( $95 \% \mathrm{Cl} 4$ to 8 ) (Table 2 ).

\section{Gross Motor Function}

Significant increases in the GMFM-88 scores were found at $T_{2}$ (Table 2). Improvements of different magnitudes were observed in the total score and in all GMFM-88 dimensions (Table 2). The confidence interval of the mean differences revealed gains relative to the patient's initial score ranging from $4 \%$ to $28 \%$. However, these gains were of small absolute magnitude (Table 2 ).

\section{Quality of Life}

Significant gains were found in the QOL in the domains of social wellbeing and acceptance, functioning, participation and physical health, and emotional wellbeing and self-esteem (Table 2). No improvement was observed in the access to services, pain and disability impact, or family health dimensions of QOL. The confidence intervals of the mean differences indicated, again, that these gains were of small absolute magnitudes (Table 2). Functioning domain showed the largest improvement over the intervention period (7 points, $95 \% \mathrm{Cl} 4$ to 9 ). 


\section{Interaction Between Outcomes and Age, Severity, Topography, and Previous Experience}

Age, severity, topography, and previous time in therapy did not impact on gains in postural control and balance (Table 3). Significant interactions were found between CP severity and topography only for dimensions $\mathrm{D}$ and $\mathrm{E}$ (Table 3). Age and previous time in therapy did not impact the gains in GMFM-88 scores (Table 3). No significant interaction of age, severity, topography, or previous time in therapy was observed in QOL domains (Table 3). In sum, out of 56 comparisons, only 4 significant interactions were found. The results indicated that severity and topography impacted the results of Dimension $D$ and $E$ of GMFM. In these dimensions, children with severe CP and the quadriplegic participants did not show as much increase as did the mild and moderate levels of $\mathrm{CP}$, as well as the hemiplegic and diplegic participants.

\section{Discussion}

The addition of hippotherapy to the rehabilitation of children with CP of distinct ages, severities, and topographies produced gains of different magnitudes in postural control and balance, gross motor function and QOL. Furthermore, changes in gross motor function (dimensions $D$ and $E$ ) were influenced by the severity and topography of the $\mathrm{CP}$. The results allowed the elaboration of a conjectural model to guide the analysis of hippotherapy effects in children with CP based on rehabilitation intervention taxonomy classification $[3,4]$.

From the TT perspective, in the motor domain, improvements in postural control and balance are the target outcomes of hippotherapy. Improvements in the postural control and balance of participants were observed in this study. As a horse moves, the center of mass of the riding individual shifts in response to the repetitive rhythmic movements of the horse's back $[25,26]$. To keep his/her trunk stabilized on a constantly moving support base, the individual is challenged to make continuous adjustments of the stabilizing core muscles (i.e., abdominal and paravertebral) and to perform movements of the head and trunk, which require postural maintenance and impact postural control $[10,25,27,28,29,30]$. The muscular activation, mainly of the head and trunk muscles, and the vestibular [25,31], proprioceptive [25,32] and visual stimuli $[25,31]$ resulting from the movement of the child-horse unit constitute the hippotherapy's mechanism of action. The active ingredient of an intervention is the specific element that causes the changes in the target outcome. In this way, the rhythmic and repetitive movement of the horse's gait and the continued displacement in the environment can be considered the active ingredients of this therapy. During therapy, the gait and displacement of the horse can be modified in relation to frequency, amplitude, direction and speed, thus requiring different postural adjustments of the child. These postural adjustments are influenced by the visual, vestibular and proprioceptive information provided by the child's displacement in the environment, afforded by the horse. Therefore, hippotherapy as a complementary therapy may provide stimuli not present in other forms of intervention for children with CP. 
ECAB scores were positively impacted by hippotherapy. However, their improvements can be considered as small and should be carefully considered if they are worthwhile. The increases of postural control and balance were consistent with several studies that have reported the benefits of hippotherapy in postural alignment [33] and static and dynamic balance [27,34,35,36,37] of children with CP. The results also revealed gains in the gross motor repertoire of the children. These benefits were highly inconsistent among the variables (and dimensions) investigated but revealed a general improvement in scores. Again, these benefits were small in terms of absolute values (ranging from 3 to 7 points out of 100). Our results revealed that, although hippotherapy produced significant increases in postural control and balance, the benefits of adding this intervention to rehabilitation programs for children with $\mathrm{CP}$ must be clinically pondered, as the observed improvements were in the magnitude that could be produced by a placebo intervention.

Despite the demonstrated benefits, this study determined that, for some outcomes, such benefits were dependent on factors such as $\mathrm{CP}$ topography and severity. The significant interactions between changes in the GMFM-88 dimensions D and E and CP topography and severity demonstrate this dependence. Gains in dimension $D$ and $E$ have been reported in previous studies [30,34,35,36,38]. However, our results suggest that such gains are not generalized for all CP types. Children with hemiplegia and diplegia had significant gains in gross motor function compared with children with quadriplegia. Similarly, gains in these dimensions were mainly observed in children with mild severity (dimension D) and with mild and moderate severity (dimension E). The significant interactions occurred due to the fact that severely disabled quadriplegic participants did not benefit from the treatment. These results may be due to the characteristics of the specific activities tested in these dimensions. Dimension D includes activities related to standing, whereas dimension E includes activities such as walking, running, jumping, kicking, jumping obstacles and climbing stairs. These activities are often performed by children with $\mathrm{CP}$ of the hemiplegic-type and by some with diplegia, but not by most children with quadriplegia or with severe CP. Even considering this fact, our results indicate that children with severe $\mathrm{CP}$ or those with the quadriplegia are not impacted by hippotherapy. However, it is important to stress that the observed improvements in less severely affected participants were still of small magnitudes and the recommendation of hippotherapy for these children should be carefully considered.

Significant (but very small) gains were observed in the psychosocial domain in the QOL dimensions of functioning, social wellbeing and acceptance, participation and physical health and emotional wellbeing and self-esteem. Among these, the dimension with the greatest mean difference between $T_{1}$ and $T_{2}$ was functioning. The confidence interval of the mean difference indicates gains between 4 and 7 points out of 100 for this variable. Thus, it appears that the observed gains in the psychosocial domain may not be of 
clinical relevance. Although QOL is not a target outcome of the hippotherapy intervention, it is considered one of the most relevant outcomes for individuals with cerebral palsy [39]. Significant improvements in the participants' postural control, balance, and gross motor function may have led to changes in the QOL functioning domain. This argument is supported by the previously demonstrated strong association between the functioning domain of QOL and motor function [40]. Gains in gross motor function can facilitate and encourage the involvement of children with CP in community activities, promoting increased functioning [41]. Another factor that may have influenced the small changes in QOL is the motivational factor experienced during hippotherapy, as noted by Debuse et al. (2009) [8]. The practice of being able to control the body and perform certain activities on a moving horse can be extremely rewarding for a child with motor disabilities, which can increase their confidence, self-esteem and selfefficacy [8,41], thus influencing their QOL [8]. In addition, the open environment and contact with nature in which this therapeutic modality is performed, and the interaction with the animal, make the therapy fun and pleasant, facilitating the engagement of the child in the activity $[8,37,41]$.

One limitation of this study was the lack of a control group; our participants attended a hippotherapy service, and it would not have been appropriate to interrupt their treatment. Without a control group, it was not possible to ascertain which changes could be attributed to the effects of hippotherapy and which changes resulted from maturation or placebo effect. However, the study was designed to document the longitudinal changes by age, intervention time, severity and CP topography subgroups. Thus, our results cannot be attributed exclusively to maturation, since not all subgroups of children with $\mathrm{CP}$ benefited from the intervention.

\section{Conclusions}

Hippotherapy, as a complementary therapy associated with conventional therapeutic modalities, produced small motor and psychosocial changes in children with CP. The benefits were, in general, of small magnitude and may not be clinically relevant. The observed changes in gross motor function were influenced by the type and severity of CP. Severely disabled quadriplegic children with cerebral palsy did not benefit from this intervention.

\section{Abbreviations}

CP: Cerebral Palsy

TT: Treatment Theory

ET: Enablement Theory

RTT: Rehabilitation Treatment Taxonomy 
GMFM: Gross Motor Function Measure

QOL: Quality of Life

GMFCS: Gross Motor Function Classification System

SES: Socioeconomic Status

ECAB: Early Clinical Assessment of Balance

CPQOL-Child: Quality of Life Questionnaire for Children with Cerebral Palsy: Questionnaire for primary caregivers

CERCAT: Equestrian Center of the Alferes Tiradentes Cavalry Regiment

\section{Declarations}

Ethics approval and consent to participate: Ethical approval of the research protocol was obtained from institutional review board of the Universidade Federal de Minas Gerais (UFMG), Brazil (approval number CAAE: 42678815.3 .0000 .5149$)$. Purpose of the study and its procedures were explained to participants and consent was obtained from the parent or legal guardian of the child and assent was secured from adolescents. Confidentiality was assured by excluding patient names and by respecting the study participants right not to participate or withdraw at any point from the study.

Consent for publication: Not applicable

Availability of data and material: The dataset analyzed during the current study is available at the OSFOpen Science Framework repository, link: https://osf.io/dashboard; Identifier: DOI 10.17605/OSF.IO/DXMK3.

Competing interests: The authors declare that they have no competing interests.

Funding: Financial support for this study was granted by the National Council for Scientific and Technological Development (CNPq; Process: 306948/2014-1), the Research Support Foundation from the State of Minas Gerais (FAPEMIG; CDS-APQ-00704-15), the Coordination of Higher Education Improvement (CAPES; Finance code 001, PROEX) and the Office of the Provost for Research from the Universidade Federal de Minas Gerais, Brazil. These funding sources were not involved in the study design, in the collection, analysis and interpretation of data, in the writing of the manuscript or in the decision to submit the article for publication.

Author contributions: JMPS, APBG, RFS, JVM, STF and MCM conceived and designed the study, participated in interpretation of results and revised the manuscript prior to submission. JMPS conducted data collection. APBG blind scored the GMFM. JVM performed the data statistical analysis. JMPS, APBG, 
MCM and STF wrote the paper. RFS and JVM critically revised all manuscript content. All authors read and approved the final manuscript.

Acknowledgements: The authors thank the parents for allowing their children to participate, the children who participated in this study and the Equestrian Center of the Alferes Tiradentes Cavalry Regiment (Regimento de Cavalaria Alferes Tiradentes / CERCAT), Minas Gerais state military police (PMMG), Belo Horizonte, Brazil. Acknowledgement is also given to the research assistants who helped in data collection.

\section{References}

1. Hart T, Tsaousides T, Zanca JM, Whyte J, Packel A, Ferraro M, et al. Toward a theory-driven classification of rehabilitation treatments. Arch Phys Med Rehabil. 2014;95(Suppl 1): S33-S44. DOI:10.1016/j.apmr.2013.05.032

2. Djikers MP, Ferraro MK, Hart T, Packel A, Whyte J, Zanca JM. Toward a rehabilitation treatment taxonomy: summary of work in progress. Phys Ther. 2014;94: 319-321. DOl:10.2522/ptj.20130999

3. Whyte J, Barret AM. Advancing the evidence base of rehabilitation treatments: a developmental approach. Arch Phys Med Rehabil. 2012;97(Suppl 1): S101-S110. DOI:10.1016/j.apmr.2011.11.040

4. Whyte J. Contributions of treatment theory and enablement theory to rehabilitation research and practice. Arch Phys Med Rehabil. 2014;97(Suppl 1):S17-S23. DOI:10.1016/j.apmr.2013.02.029

5. Zadnikar M, Kastrin A. Effects of hippotherapy and therapeutic horseback riding on postural control or balance in children with cerebral palsy: a meta-analysis. Dev Med Child Neurol. 2011;53: 684-691. DOI:10.1111/j.1469-749.2011.03951

6. Whalen $\mathrm{CN}$, Case-Smith J. Therapeutic effects if horseback riding on gross motor function in children with cerebral palsy: a systematic review. Phys Occup Ther Pediatr. 2012;32: 229-242. DOI:10.3109/01942638.2011.619251

7. Meregliano G. Hippotherapy. Phys Med Rehabil Clin North Am. 2004;15: 843-854. DOI:10.1016/j.pmr.2004.02.002

8. Debuse D, Gibb C, Chandler C. Effects of hippotherapy on people with cerebral palsy from the users' perspective: a qualitative study. Phys Theor Pract. 2009;25(3): 174-192.

DOI:10.1080/09593980902776662.

9. Bertoti DB. Effect of therapeutic horseback riding on posture in children with cerebral palsy. Phys Ther. 1998; 68: 1505-1512. DOI: 10.1093/ptj/68.10.1505

10. Shurtleff TL, Standeven JW, Engsberg JR. Changes in dynamic trunk/head stability and functional reach after hippotherapy. Arch Phys Med Rehabil. 2009;90: 1185-1195.

DOI:10.1016/j.apmr.2009.01.026 
11. Palisano R, Rosenbaum P, Walter S, Russel D, Wood E, Galuppi B. Development and reliability of a system to classify gross motor function in children with cerebral palsy. Dev Med Child Neurol. 1997; 39: 214-223.

12. Hiratuka E, Matsukura TS, Pfeifer LI. Cross-cultural adaptation of the Gross Motor Function System into Brazilian-Portuguese (GMFCS). Bras J Phys Ther. 2010;14(6): 537-544. ISSN: 1413-3555

13. Brazilian Association of Research Companies (ABEP). Brazilian Criteria for Economic Classification, 2014. Available from: http://www.abep.org/criterio-brasil

14. McCoy SW, Bartlett DJ, Yocum A, Jeffries L, Fiss AL, Chiarello L, et al. Development and validity of the early assessment of balance for young children with cerebral palsy. Dev Neurorehabil. 2014; 17: 375-383. DOI:10.3109/17518423.2013.827755

15. Randall KE, Bartlett DK, McCoy SW. Measuring postural stability in young children with cerebral palsy: a comparison of 2 instruments. Pediatr Phys Ther, 2014;26: 332-337.

DOI:10.1097/PEP.0000000000000062

16. Cyrillo LT, Galvão MCS. Gross Motor Function Measure [GMFM-66 \& GMFM-88] (Portuguese translated manual). São Paulo: Memnon; 2011.

17. Russel DJ, Rosenbaum PL, Cadman DT, Gowland C, Hardy S, Jarvis S. The gross motor function measure: a means to evaluate the effects of physical therapy. Dev Med Child Neurol. 1989; 31: 341352.

18. Russel DJ, Avery LM, Rosenbaum PL, Raina, PS, Walter SD, Palisano RJ. Improved scaling of the gross motor function measure for children with cerebral palsy: evidence of reliability and validity. Physical Therapy, 2000;80: 873-885.

19. Waters E, Maher E, Salmon L, Reddihpugh D, Boyd R. Developing a new quality of life scale for children with cerebral palsy. Child: Care, Health and Develop. 2005; 31: 127-135.

DOI:10.3109/09638288.2012.669021

20. Braccialli LMP, Braccialli AC, Sankako AN, Dechandt MLC, Almeida VC, Carvalho SMR. Quality of life questionnaire for children with cerebral palsy (CP QOL-CHILD): Translation and cultural adaptation to the Brazilian Portuguese language. J Hum Growth and Develop. 2013; 23(2): 154-163. DOI:http://dx.doi.org/10.7322/jhgd.61289

21. Casady RL, Nichols-Larsen DS. The effect of hippotherapy on ten children with cerebral palsy. Pediatr Phys Ther. 2004;16: 165-172. DOI:10.1097/01.PEP.0000136003.15233.0C

22. Park ES, Rha DW, Shin JS, Kim S, Jung S. Effects of hippotherapy on gross motor function and functional performance of children with cerebral palsy. Yonsei Med J. 2014;55(6): 1736-1742. DOI:10.3349/ymj.2014.55.6.1736

23. Davis E, Davies B, Wolfe R, Raadsveld R, Heine B, Thomason P, et al. A randomized controlled trial of the impact of therapeutic horse riding on the quality of life, health, and function of children with cerebral palsy. Dev Med Child Neurol. 2009;51: 111-119. D0I:10.1111/j.1469-8749.2008.03245.x

24. Hammil D, Washington $K$, White OR. The effect of hippotherapy on postural control in sitting for children with cerebral palsy. Phys Occup Ther Pediatr. 2007;27: 23-42. 
25. Moraes AG, Copetti F, Ângelo VR, Chiavoloni L, David AC. Hippotherapy on postural balance in the sitting position of children with cerebral palsy - Iongitudinal study. Phys Theory Pract 2018, Jun 11:1-8. DOI:10.1080/09593985.2018.1484534

26. Galloux P, Richard N, Dronka T, Leard M, Perrot A, Jouffroy JL, et al. Analysis of equine gait using three-dimensional accelerometers fixed on the saddle. Equine Vet J. 1994; 17(Suppl.): 44-47. DOI:10.1111/j.2042-3306.1994.tb04872.x

27. Temcharoensuk P, Lekskulchai R, Akamanon C, Ritruechai P, Sutcharitpongsa S. Effect of horseback riding simulator on sitting ability of children with cerebral palsy: a randomized controlled trial. J Phys Ther Sci. 2015;27: 273-277. DOI:10.1589/jpts.27.273

28. Pantall A, Barton S, Collins P. Surface electromyography of abdominal and spinal muscles in adults' horse riders during rising trot. 2009. Paper presented at the 27th International conference on Biomechanics in Sport, Limerick, Ireland. DOI:10.1079/ECEP200420

29. Tereda K, Mullineaux DR, Kiyotada K, Claytin HM. Electromyography activity of the rider's muscle at trot. Equine Comp Exer Physiol. 2004;1: 193-198. DOI:10.1079/ECEP200420

30. Champagne D, Corriveu H, Dugas C. Effect of hippotherapy on motor proficiency and function in children with cerebral palsy who walk. Phys Occup Ther Pediatr. 2017;37(1):51-63.

DOI:10.3109/01942638.2015.1129386

31. Cherng $\mathrm{R}$, Liao $\mathrm{H}$, Leung $\mathrm{H}$, Hwang A. The effectiveness of therapeutic horseback riding in children with spastic cerebral palsy. Adapt Phys Activ Q. 2004; 21:103-121. D0I:10.1123/apaq.21.2.103

32. Erdman EA, Pierce SR. Use of hippotherapy with a boy after traumatic brain injury; a case study. Pediatr Phys Ther. 2016;28: 109-116. DOI:10.1097/PEP.0000000000000204

33. El-Meniawy GH, Thabet NS. Modulation of back geometry in children with spastic diplegic cerebral palsy via hippotherapy training. Egypt J Med Hum Gen. 2012;13: 63-71. DOI:

10.1016/j.ejmhg.2011.10.004

34. Kwon JY, Chang HJ, Lee JY, Ha Y, Lee PK, Kim YH. Effects of hippotherapy on gait parameters in children with bilateral spastic cerebral palsy. Arch Phys Med Rehabil. 2011;92: 774-779.

DOI:10.1016/j.apmr.2010.11.031

35. Chang HJ, Kwon JY, Lee JY, Kim YH. The effects of hippotherapy on the motor function of children with spastic bilateral cerebral palsy. J Phys Ther Sci. 2012;24: 1277-1280. DOI:10.1589/jpts.24.1277

36. Lee CW, Kim SG, Na SS. The effect of hippotherapy and a horse riding simulator on the balance of children with cerebral palsy. J Phys Ther Sci. 2014;26: 423-425. DOI:10.1589/jpts.26.423

37. Kwon JY, Chang HJ, Yi SH, Lee JY, Shin HY, Kim YH. Effect of hippotherapy on gross motor function in children with cerebral palsy a randomized controlled trial. J Altern Complement Med. 2015;21(1): 15-21. DOI:10.1089/acm.2014.0021

38. Drnach M, O'Brien PA, Kreger A. The effect of a 5-week therapeutic horseback riding program on gross motor function in a child with cerebral palsy: a case study. J Altern Complement Med. 2010;16: 1003-1006. DOI:10.1089/acm.2010.0043 
39. Vargus-Adams JN, Martin LK. Measuring what matters in cerebral palsy: a breadth of important domains and outcome measures. Arch Phys Med Rehabil. 2009;90: 2089-2095.

DOI:10.1016/j.apmr.2009.06.018

40. Shelly A, Davis E, Waters E, Mackinnon A, Reddinhough D, Boyd R, et al. The relationship between quality of life and functioning for children with cerebral palsy. Dev Med Child Neurol. 2008;50: 199203. DOI:10.1111/j.1469-8749.2008.02031.x

41. Frank A, McLoskey S, dole RL. Effect of hippotherapy on perceived self-competence and participation in a child with cerebral palsy. Pediatr Phys Ther. 2011;23: 301-38.

DOI:10.1097/PEP.0b013e318227caac

\section{Tables}

TABLE 1. Clinical and demographic characteristics of children with $\mathrm{CP}(\mathrm{n}=31)$ and their caregivers 


\begin{tabular}{|c|c|}
\hline Characteristics of children with cerebral palsy (CP) & Descriptive \\
\hline \multicolumn{2}{|l|}{ Sex* } \\
\hline Male & $19(61)$ \\
\hline Female & $12(39)$ \\
\hline \multicolumn{2}{|l|}{ GMFCS* } \\
\hline I & $02(6)$ \\
\hline II & $07(23)$ \\
\hline III & $07(23)$ \\
\hline IV & $08(25)$ \\
\hline $\mathrm{V}$ & $07(23)$ \\
\hline \multicolumn{2}{|l|}{ Type of CP* } \\
\hline Quadriplegia & $13(42)$ \\
\hline Diplegia & $13(42)$ \\
\hline Hemiplegia & $05(16)$ \\
\hline \multicolumn{2}{|l|}{ Previous Time in Hippotherapy* } \\
\hline 3-6 months & $20(65)$ \\
\hline$>6$ months & $11(35)$ \\
\hline Hippotherapy Sessions ${ }^{\dagger}$ & $23 \pm 1$ \\
\hline \multicolumn{2}{|l|}{ Conventional Therapy Attended* } \\
\hline Physical Therapy & $25(80)$ \\
\hline Occupational Therapy & $22(71)$ \\
\hline Others $^{\ddagger}$ & $21(68)$ \\
\hline None & $03(10)$ \\
\hline Age (years) ${ }^{\dagger}$ & $8 \pm 2$ \\
\hline \multicolumn{2}{|l|}{ Age Groups* } \\
\hline 04-07 years & $17(55)$ \\
\hline 08-12 years & $14(45)$ \\
\hline \multicolumn{2}{|l|}{ Family Socioeconomic Level* } \\
\hline $\mathrm{A}$ & $01(3)$ \\
\hline B & $15(48)$ \\
\hline $\mathrm{C}$ & $11(36)$ \\
\hline D-E & $04(13)$ \\
\hline Characteristics of Caregivers & Descriptive \\
\hline Age (years) ${ }^{\dagger}$ & $42 \pm 9$ \\
\hline \multicolumn{2}{|l|}{ Relationship with Child/Youth* } \\
\hline Mother/Father & $27(87)$ \\
\hline Grandmother/Grandfather & $04(13)$ \\
\hline \multicolumn{2}{|l|}{ Education* } \\
\hline Elementary School & 09 (29) \\
\hline High School & $12(39)$ \\
\hline College & $15(49)$ \\
\hline
\end{tabular}


*Numbers indicate frequency and (\%).

${ }^{\dagger}$ Numbers indicate values of mean and \pm SD.

‡Speech pathology, psychology and academic tutor.

Note: Family Socioeconomic Level = The 2014 Brazilian Economic Classification Criterion ${ }^{12}$ and quantifies the purchasing power of urban households based on information on the presence and quantity of household appliances, the degree of education of the head of the household and access to public services (tap water and paved streets). This criterion produces a total score that is converted into SES strata; class A indicates higher SES families, followed by classes B, C, D and E.

TABLE 2. Mean (SD) for each outcome at each time and mean (95\% CI) difference between times.

\begin{tabular}{|c|c|c|c|}
\hline \multirow[b]{2}{*}{ OUTCOME } & \multicolumn{2}{|c|}{ Times } & Difference between times \\
\hline & $\begin{array}{c}\text { Month } \\
0\end{array}$ & $\begin{array}{c}\text { Month } \\
6\end{array}$ & $\begin{array}{c}\text { Month } 6 \text { - Month } 0 \text { ( } 95 \% \text { confidence interval of } \\
\text { difference) }\end{array}$ \\
\hline Balance & $40(32)$ & $46(33)$ & 6 (4 to 8$)$ \\
\hline \multicolumn{4}{|l|}{ ECAB (0-100) } \\
\hline \multicolumn{4}{|l|}{ Motor ability } \\
\hline \multicolumn{4}{|l|}{ GMFM-88 (0-100) } \\
\hline Total & $43(30)$ & $48(31)$ & 5 (4 to 7 ) \\
\hline $\mathrm{A}$ & $71(31)$ & 77 (28) & 6 (3 to 8 ) \\
\hline $\mathrm{B}$ & $58(33)$ & $64(33)$ & 6 (3 to 10$)$ \\
\hline $\mathrm{C}$ & $38(36)$ & $45(39)$ & 7 (3 to 10 ) \\
\hline $\mathrm{D}$ & $27(34)$ & $30(36)$ & $3(2$ to 6$)$ \\
\hline $\mathrm{E}$ & $21(29)$ & $25(31)$ & 4 (2 to 6$)$ \\
\hline \multicolumn{4}{|l|}{ Quality of Life } \\
\hline \multicolumn{4}{|l|}{ CPQOL-Child (0-100) } \\
\hline Social wellbeing \& acceptance & $80(9)$ & $84(9)$ & 4 (2 to 7$)$ \\
\hline Functioning & $66(11)$ & $73(11)$ & 7 (4 to 9 ) \\
\hline Participation \& physical health & $68(12)$ & $73(10)$ & 5 (2 to 7$)$ \\
\hline $\begin{array}{l}\text { Emotional wellbeing \& self- } \\
\text { esteem }\end{array}$ & $83(9)$ & $87(8)$ & $4(1$ to 6$)$ \\
\hline Access to services & $76(10)$ & $78(7)$ & $2(-2$ to 4$)$ \\
\hline Pain \& disability impact & $27(15)$ & $27(13)$ & $0(-4$ to 4$)$ \\
\hline Family health & $70(17)$ & $72(15)$ & $2(-1$ to 5$)$ \\
\hline
\end{tabular}

$\mathrm{ECAB}=$ Early Clinical Assessment of Balance. GMFM = Gross Motor Function Measure. Dimensions of GMFM = Dimension A: Lying and Rolling; Dimension B: Sitting; Dimension C: Crawling and Kneeling; Dimension D:

Standing; Dimension E: Walking, Running and Jumping. CPQOL = Quality of Life Questionnaire for Children with Cerebral Palsy: Questionnaire for primary caregivers (CPQOL-Child). 
TABLE 3. Mean (SD) for each outcome at each time and mean difference (95\% CI) by age, severity, topography of $\mathrm{CP}$ and previous hippotherapy time. 


\begin{tabular}{|c|c|c|c|c|c|}
\hline \multirow[b]{2}{*}{ Outcome } & \multirow[b]{2}{*}{ Factor } & \multicolumn{2}{|c|}{ Time } & \multirow{2}{*}{$\begin{array}{c}\text { Mean Difference } \\
\text { ( } 95 \% \text { confidence } \\
\text { interval of difference) }\end{array}$} & \multirow{2}{*}{$\begin{array}{l}\text { Interaction } \\
\text { factor x time } \\
\text { (p-value) }\end{array}$} \\
\hline & & $\begin{array}{c}\text { Month } \\
0\end{array}$ & $\begin{array}{c}\text { Month } \\
6\end{array}$ & & \\
\hline \multicolumn{6}{|l|}{ Balance } \\
\hline \multirow[t]{22}{*}{ ECAB (0-100) } & Age & & & & $0.12^{*}$ \\
\hline & 4-7 years & 30 & 35 & $4(1 \text { to } 5)^{\dagger}$ & \\
\hline & 8-12 years & (30) & (31) & $7(3 \text { to } 11)^{\dagger}$ & \\
\hline & & $\begin{array}{c}52 \\
(30)\end{array}$ & $\begin{array}{c}60 \\
(30)\end{array}$ & & \\
\hline & Severity & & & & $0.63^{*}$ \\
\hline & Mild & 82 & $91(8)$ & $8(0 \text { to } 13)^{\dagger}$ & \\
\hline & Moderate & (16) & 43 & $5(4 \text { to } 9)^{\dagger}$ & \\
\hline & Severe & 37 & (19) & $5(1 \text { to } 7)^{\dagger}$ & \\
\hline & & (18) & 21 & & \\
\hline & & $\begin{array}{c}16 \\
(12)\end{array}$ & $(12)$ & & \\
\hline & Topography & & & & $0.97^{*}$ \\
\hline & Diplegia & 59 & 66 & $5(4 \text { to } 9)^{\dagger}$ & \\
\hline & Hemiplegia & (28) & (29) & $5(3 \text { to } 11)^{\dagger}$ & \\
\hline & Quadriplegia & 55 & 62 & $5(2 \text { to } 7)^{\dagger}$ & \\
\hline & & (35) & (36) & & \\
\hline & & 15 & 20 & & \\
\hline & & (12) & (12) & & \\
\hline & $\begin{array}{l}\text { Previous time in } \\
\text { hippotherapy }\end{array}$ & & & & \\
\hline & 3-6 months & 46 & 52 & $5(3 \text { to } 9)^{\dagger}$ & $0.93^{*}$ \\
\hline & $>6$ months & (35) & (35) & $5(1 \text { to } 11)^{\dagger}$ & \\
\hline & & 30 & 36 & & \\
\hline & & (23) & (27) & & \\
\hline \multicolumn{6}{|c|}{ Motor ability } \\
\hline \multicolumn{6}{|c|}{ GMFM-88 (0-100) } \\
\hline \multirow[t]{20}{*}{ Total Score } & Age & & & & \\
\hline & 4-7 years & 33 & 38 & 5 (3 to 7 ) & 0.77 \\
\hline & 8-12 years & (30) & (32) & 6 (3 to 8 ) & \\
\hline & & 55 & 61 & & \\
\hline & & (26) & (26) & & \\
\hline & Severity & & & & \\
\hline & Mild & 79 & $84(9)$ & $4(3 \text { to } 9)^{\dagger}$ & \\
\hline & Moderate & (10) & 57 & $6(4 \text { to } 8)^{\dagger}$ & $0.52^{*}$ \\
\hline & Severe & 51 & (21) & $4(2 \text { to } 7)^{\dagger}$ & \\
\hline & & (20) & 23 & & \\
\hline & & 18 & (15) & & \\
\hline & & (13) & & & \\
\hline & Topography & & & & \\
\hline & Diplegia & 64 & 70 & 5 (4 to 7 ) & \\
\hline & Hemiplegia & (20) & (21) & $4(0.4$ to 10$)$ & 0.98 \\
\hline & Quadriplegia & 56 & 61 & 5 (2 to 8 ) & \\
\hline & & (34) & (34) & & \\
\hline & & 17 & 22 & & \\
\hline & & (13) & $(16)$ & & \\
\hline & & Page 1 & 25 & & \\
\hline
\end{tabular}


Previous time in

hippotherapy

3-6 months

$>6$ months

49

(31)

53

(32)

$33 \quad 40$

(27) (29)

Age

Dimension A

Topography

Diplegia

Hemiplegia

Quadriplegia

Previous time in

hippotherapy

3-6 months

$>6$ months

Dimension B

Age

4-7 years

8-12 years

Severity

Mild

Moderate

Severe

Topography

Diplegia

Hemiplegia

Quadriplegia

(36) (37)

$72 \quad 76$

(25) (22)

(36) (33)

$87 \quad 90$

(12) (11)

93 (6) $96(4)$

$88 \quad 92(7)$

(10) 57

$50 \quad$ (30)

(32)

92 (4) 95 (4)

$81 \quad 86$

(18) (17)

$46 \quad 54$

(32) (30)

$76 \quad 81$

(31) (28)

$61 \quad 69$

(29) (27)

$\begin{array}{cc}46 & 53 \\ (36) & (37) \\ 72 & 76 \\ (25) & (22)\end{array}$

91 (7) 95 (7)

$75 \quad 80$

(24) (22)

$30 \quad 38$

(21) (26)

$83 \quad 88$

(19) (17)

$71 \quad 73$

(30) (29)

$28 \quad 37$

(21) (27)
4 (3 to 6)

0.07

7 (4 to 10 )

0.09*

$2(0 \text { to } 4)^{\dagger}$

$2(0 \text { to } 6)^{\dagger}$

$2(0 \text { to } 6)^{\dagger}$

$4(0 \text { to } 14)^{\dagger}$

$0.61 *$

$2(1 \text { to } 4)^{\dagger}$

$0{\text { (-7 to } 17)^{\dagger}}^{\dagger}$

$0.48^{*}$

$4(3 \text { to } 14)^{\dagger}$

$0.30 *$

$2(0 \text { to } 5)^{\dagger}$

$6(0 \text { to } 14)^{\dagger}$

$3(2 \text { to } 10)^{\dagger}$

0.78*

4 (2 to 7$)^{\dagger}$

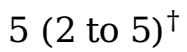

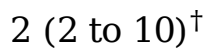

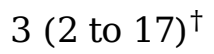

0.92*

$5{\text { (3 to } 9)^{\dagger}}^{\dagger}$

$2(-4 \text { to } 8)^{\dagger}$

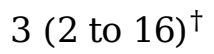

$0.52^{*}$

Previous time in

hippotherapy

3-6 months

$3(2 \text { to } 5)^{\dagger}$

$0.06^{*}$ 


$\begin{array}{cccc} & 65 & 69 & 8(2 \text { to } 25)^{\dagger} \\ (33) & (34) & \\ 45 & 56 \\ (32) & (33)\end{array}$

Dimension C

Age

4-7 years

$29 \quad 34$

$0\left(^{0} \text { to } 7\right)^{\dagger}$

0.16*

(38) (42)

8-12 years

$49 \quad 59$

(32) (31)

Severity

Mild

Moderate

$78 \quad 84$

(16) (17)

Severe

$51 \quad 61$

(32) (38)

9 (12) $\quad 14$

(21)

\section{Topography}

Diplegia

Hemiplegia

Quadriplegia

$\begin{array}{cc}65 & 72 \\ (25) & (29) \\ 49 & 53 \\ (46) & (46) \\ 8(12) & 14 \\ & (22)\end{array}$

Previous time in

hippotherapy

3-6 months

$>6$ months

Dimension D

\section{Age}

4-7 years

8-12 years

$44 \quad 50$

(37)

27

36

(33) (37)

$8(0 \text { to } 19)^{\dagger}$

$0.45^{*}$

$7(0 \text { to } 21)^{\dagger}$

$0\left(0 \text { to }_{10}\right)^{\dagger}$

0.70

8 (2 to 13$)$
$5(-1$ to 10$)$
$6(-1$ to 13$)$

8 (2 to 13$)$
$5(-1$ to 10$)$
$6(-1$ to 13$)$

$2(0 \text { to } 11)^{\dagger}$

$0.42^{*}$

$7(0 \text { to } 10)^{\dagger}$

$18 \quad 20$

(30) (34)

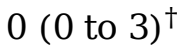

0.13*

$37 \quad 42$

(37) (37)

\section{Severity}

Mild

Moderate

Severe

$71 \quad 78$

(14) (10)

25 (3) $\quad 29$

1 (2) (32)

2 (5)

Topography

Diplegia

Hemiplegia

$47 \quad 51$

(33) (35)

Quadriplegia

Previous time in

$43 \quad 49$

(42) (44)

1 (2) 2 (5)

$5(0 \text { to } 5)^{\dagger}$

$5\left(^{3} \text { to } 8\right)^{\dagger}$

$5(0 \text { to } 8)^{\dagger}$

$0(0 \text { to } 0)^{\dagger}$

$0.01 *$ hippotherapy

3-6 months

$32 \quad 35$

(36) (38)

$3(0 \text { to } 5)^{\dagger}$

$0.70^{*}$ 
Dimension E

\section{Quality of life}

CPQOL-Child (0-100)

Social Wellbeing and

Acceptance
Age

4-7 years

8-12 years

$13 \quad 17$

(23) (28)

$31 \quad 35$

(32) (33)

Severity

Mild

Moderate

Severe

\section{Topography}

Diplegia

Hemiplegia

Quadriplegia

Previous time in

hippotherapy

3-6 months

$>6$ months
$60 \quad 67$

(15) (16)

$16 \quad 22$

(20) (20)

1 (3) 1 (4)

36(29) 42

$38 \quad$ (28)

(36) 45

1 (3) (40)

1 (5)

$26 \quad 31$

(31) (32)

$0(0 \text { to } 8)^{\dagger}$

0.98*

$1(0 \text { to } 4)^{\dagger}$

$0.00^{*}$

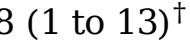

$0(0 \text { to } 0)^{\dagger}$

$4(1 \text { to } 13)^{\dagger}$

$8(1 \text { to } 11)^{\dagger}$

$0(0 \text { to } 0)^{\dagger}$

$0.00 *$

$3(0 \text { to } 8)^{\dagger}$

$0.14^{*}$

$13 \quad 16$

(23) (28)

Age

4-7 years

8-12 years

$81 \quad 87(9)$

(10) $82(7)$

78 (8)

Severity

Mild

Moderate

Severe

\section{Topography}

Diplegia

Hemiplegia

Quadriplegia

Previous time in

hippotherapy

3-6 months

$>6$ months

$80 \quad 85(9)$

(10) $84(7)$

80 (7)

$78 \quad 83(8)$

(10) 84

$80 \quad$ (12)

(12) 85 (7)

80 (7)

77 (9) 85 (9)

$80 \quad 81$

(12) (12)

80 (7) 85 (8)
6 (2 to 9 )

0.33

3 (0.4 to 6$)$

$5(0 \text { to } 7)^{\dagger}$

0.95*

9 (5 to 12$)$

0.05 


$\begin{array}{cccc}\text { 8-12 years } & 63 & 72 & 4(1 \text { to } 7) \\ & (11) & (11) & \\ 69(9) & 73 & \end{array}$

\section{Severity}

Mild

$69 \quad 78$

(11)

Moderate

(11) (14)

Severe

$68 \quad 76$

$9(4 \text { to } 14)^{\dagger}$

$8(0 \text { to } 15)^{\dagger}$

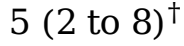

(10) (10)

$63 \quad 68(7)$

(11)

\section{Topography}

Diplegia

Hemiplegia

Quadriplegia

hippotherapy

3-6 months

$>6$ months

Participation \& Physical

Age

Health

$\begin{array}{lcc}\text { 4-7 years } & 70 & 75 \\ \text { 8-12 years } & (12) & (10) \\ & 65 & 70 \\ & (11) & (10) \\ \text { Severity } & & \\ \text { Mild } & 69 & 76 \\ \text { Moderate } & (14) & (13) \\ \text { Severe } & 65 & 69 \\ & (13) & (13) \\ & 69 & 73(8) \\ & (11) & \\ \text { Topography } & & \\ \text { Diplegia } & 67 & 72 \\ \text { Hemiplegia } & (13) & (11) \\ \text { Quadriplegia } & 70 & 73 \\ \text { Previous time in } & (13) & (16) \\ \text { hippotherapy } & 68 & 73(8) \\ \text { 3-6 months } & (11) & \\ \text { > 6 months } & & \\ & & 70 \\ & 70 & (12) \\ & (12) & 74(8) \\ & 65 & \\ & (12) & \\ & & \end{array}$

Emotional Wellbeing and Age

Self-esteem

4-7 years

8-12 years
69 (8) $\quad 77$

$67 \quad$ (11)

(13) 75

63

(13)

(12)

67 (8)

$69 \quad 75$

(10) (11)

$61 \quad 68$

(11) (10)

$5(2 \text { to } 9)^{\dagger}$

$5(1 \text { to } 15)^{\dagger}$

$7(2 \text { to } 11)^{\dagger}$

$5{\text { (5 to } 9)^{\dagger}}^{\dagger}$

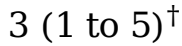

$0.20 *$

0.77*

5$$
\text { 10) }
$$

70

5 (1 to 8)

0.97

5 (0.5 to 9 )

$0.53^{*}$

$7(4 \text { to } 10)^{\dagger}$

$4(-4 \text { to } 12)^{\dagger}$

$4(-0.3 \text { to } 8)^{\dagger}$

5 (1 to 9 )

4 (-8 to 16$)$

0.90

5 (1 to 9 )

3 (0.5 to 5$)$

0.05

9 (3 to 14)

$\begin{array}{cccc}83 & 88(8) & 4(0 \text { to } 8)^{\dagger} & 0.09 * \\ (10) & 85(9) & 2(-2 \text { to } 4)^{\dagger} & \end{array}$




\section{Severity}

Mild

Moderate

Severe

Topography

Diplegia

Hemiplegia

Quadriplegia

Previous time in

hippotherapy

3-6 months

$>6$ months
$87(9) \quad 90(9)$

83 (9) $87(7)$

81 (9) 85 (8)

85 (9) 89 (7)

85

(11)

$80(9)$

89

(11)

$83(7)$

84 (9) 88 (8)

$82 \quad 84(8)$

*Nonparametric test.

${ }^{\dagger}$ Median of group difference and interquartile range (P25, P75) interval.

$\mathrm{ECAB}=$ Early Clinical Assessment of Balance. $\mathrm{GMFM}=$ Gross Motor Function Measure. Dimensions of GMFM = Dimension A: Lying and Rolling; Dimension B: Sitting; Dimension C: Crawling and Kneeling; Dimension D: Standing; Dimension E: Walking, Running and Jumping. CPQOL = Quality of Life Questionnaire for Children with Cerebral Palsy: Questionnaire for primary caregivers (CPQOL-Child).

\section{Figures}




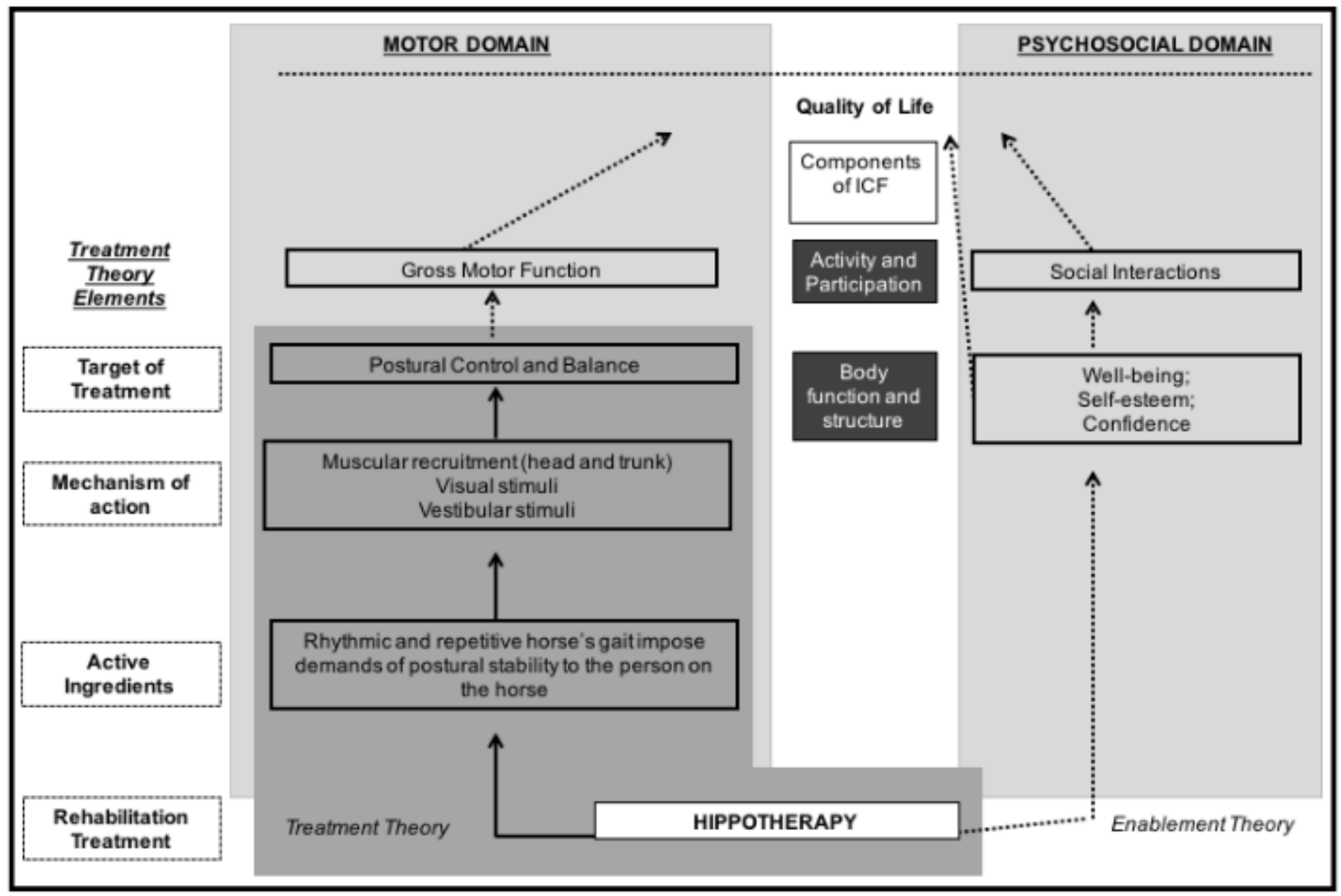

\section{Figure 1}

Effects of hippotherapy according to treatment theory and enablement theory Legend: --> Elements of the treatment theory; -> Elements of the enablement theory

\section{Supplementary Files}

This is a list of supplementary files associated with this preprint. Click to download.

- CONSORT2010FlowDiagram.doc

- CONSORT2010ChecklistManuscriptHippotherapy.doc 